\title{
The evolution process of warm season intense regional rainfall events in Yaan
}

\author{
Xuelin $\mathrm{Hu}^{1,2} \cdot$ Weihua Yuan ${ }^{1}$ (D) Rucong $\mathrm{Yu}^{3} \cdot$ Minghua Zhang ${ }^{4,5}$
}

Received: 26 June 2019 / Accepted: 4 February 2020 / Published online: 13 February 2020

(c) The Author(s) 2020

\begin{abstract}
Accurate simulation and prediction of intense precipitation events require better understanding of their physical mechanisms. This study uses Yaan - a place with regional maximum rainfall in central China - to investigate the cause and process of intense precipitation. Hourly rain gauge records and the new ERA5 reanalysis are used to characterize the evolution process of warm season intense regional rainfall events (RREs) in Yaan and its associated three-dimensional circulation. Results show that before the start of the Yaan intense RREs, moderate rainfall amount (frequency) appears northeast of the key region. The rainfall then moves southward in the following several hours along the eastern periphery of the Tibetan Plateau where it reaches peak. It then moves to and end up in the south and southeast Sichuan Basin. The progression of the RREs is found to be associated with a counter-clockwise rotation of anomalous surface winds associated with a developing mesoscale surface low-pressure center, which is further associated with the southeastward progression of a large-scale synoptic scale wave. The easterly phase of the winds in the counter-clockwise rotation causes upslope motion perpendicularly toward the terrain that leads to maximum rainfall. The findings illustrate how large-scale circulations, mesoscale systems, and specific topographic features interact to create the RREs evolution in Yaan.
\end{abstract}

Keywords Intense precipitation $\cdot$ Regional rainfall event $\cdot$ Complex terrain $\cdot$ Multi-scale interaction

\section{Introduction}

Regional precipitation has been a subject of intensive research because of its varied physical mechanisms and extensive economical and societal impacts (e.g., Teixeira and Satyamurty 2007; Li and Yu 2014; Chen and Zhai 2015). Despite the steady improvement in predicting precipitation (Fritsch and Carbone 2004), the skill associated with warm season heavy rainfall prediction remains low (Carbone

Weihua Yuan

yuanweihua@mail.iap.ac.cn

1 LASG, Institute of Atmospheric Physics, Chinese Academy of Sciences, Beijing, China

2 University of Chinese Academy of Sciences, Beijing, China

3 LaSW, Chinese Academy of Meteorological Sciences, China Meteorological Administration, Beijing, China

4 School of Marine and Atmospheric Sciences, Stony Brook University, Stony Brook, NY, USA

5 International Center for Climate and Environmental Sciences/IAP, Chinese Academy of Sciences, Beijing, China et al. 2002). Complex orography is one of the factors that can significantly influence regional precipitation (Smolarkiewicz and Rotunno 1989; Smith and Barstad 2004; Chen and Lin 2005). Although the accuracy of numerical models has increased in the past several decades (Bonner 1989; Bauer et al. 2015), long-term bias still exists in the precipitation simulations within complex terrain (Meehl and Arblaster 1998; Yu et al. 2000; Phillips and Gleckler 2006; Xu and $\mathrm{Xu}$ 2012; Gao et al. 2015). Therefore, there is the need to better understand the physical processes of how complex terrain impact rainfall by using observations. Located on the eastern periphery of the Tibetan Plateau (TP) and the western edge of the Sichuan Basin (SCB), Yaan is characterized by both windward slope and bell-shaped topography. The complex terrain and its interaction with atmospheric circulation resulted Yaan a "rain city" with the maximum annual precipitation amount and rainy days within inland China (Xi 1992; Peng et al. 1994; Li et al. 2010). Yaan thus becomes an ideal place for studying rainfall and its interaction with complex orography.

The spatiotemporal characteristics of rainfall events reflect the evolution properties of the rainfall process, the 
study of which is conducive to understanding the mechanisms. Based on available hourly rain gauge records, the sub daily characteristics of precipitation have been comprehensively revealed within inland China (see, among others, Yu et al. 2007a, b; Li et al. 2008, 2011; Yuan et al. 2010; Zheng et al. 2019). For instance, the well-known nocturnal feature of precipitation in the Sichuan Basin was reported long ago (Lee 1942) and is thought to be connected with the inertial oscillation of the boundary layer low-level jet (Zhang et al. 2019). This nocturnal precipitation shows a prominent eastward timing delay, that is, the diurnal peak of precipitation occurs at early-night in the western basin whereas at late-night in the center and east of the basin (Jin et al. 2013). Chen et al. (2017) investigated the nocturnal rainfall over the eastern periphery of TP and its relationship with rainfall events in adjacent regions. They found that there were some rainfall events over the eastern periphery of TP, especially long intense rainfall events, that are closely related to upstream convection activities. Other hourly characteristics includes the asymmetry of rainfall process (Yu et al. 2013), which means rainfall events usually reach the maximum in short period and then experience a relatively longer retreat to the end of the event, especially over complex terrain. Meanwhile, there are also many case studies analyzing and revealing fine-scale characteristics of the heavy precipitation over Yaan and surrounding areas (see, among others, Peng et al. 2008; Zhou and Wu 2015; Li et al. 2016; Wang et al. 2017). For instance, using the TRMM data combined with surfaces observations, Wang et al. (2017) showed the horizontal structure of a heavy rainfall event over the eastern slope of TP, finding that the rainfall system consisted of a stratiform precipitation cloud cluster and several convective precipitation clouds characterized by high rainfall intensity. Li et al. (2016) gave the hourly time series of rainfall amount at one single station using the rain gauge records, showing that the long-lasting rainfall event in that case was actually composed of several short-term convective precipitations. However, the research is sparse on the overall fine-scale spatiotemporal evolution characteristics of Yaan rainfall events from a climate perspective.

The characteristics and evolution process of rainfall events are often controlled by atmospheric circulations. Atmospheric systems such as fronts, troughs and jets could have influence on the rainfall to different degrees under different conditions (Carbone et al. 1990; Konrad 1997). The evolution process is related to the changing processes of these systems. For example, Chen et al. (2010) investigated the diurnal phase change along the Yangtze River and found the clockwise rotation of the nocturnal southwesterly to be the main reason. Numerous studies have described the circulation of rainfall in Yaan. Synoptic research shows that the forecasting of heavy rainfall in Yaan should consider the western Pacific subtropical high, low-level jet, low vortex from the TP, orographic vortex and even typhoons (Zeng et al. 1994; Peng et al. 2008). In summarizing the typical heavy rainfall conditions in northern Yaan, Wang (1977) pointed out the crucial role of the subtropical high in supplementing of warm wet air and in blocking the cold air from the north. Peng et al. (1994) then emphasized the influence of the orographic low on the $850 \mathrm{hPa}$ level and found that the divergent field of the South Asian high and atmospheric stratification instability may also have an influence. How these systems change in collaborating with the evolution of precipitation has not been clearly elucidated. On the other hand, some research (e.g., Yu et al. 2004; Xin et al. 2006) stressed the role of temperature anomaly in the troposphere which may influence the circulation. For example, Sun et al. (2018) investigated the leading circulations of propagating and nonpropagating rainfall in North China and found that the distribution of the upper-tropospheric temperature anomaly greatly affects the propagation of the rainfall. Therefore, tropospheric temperature anomalies may play a key role in the stereoscopic structure of rainfall circulation. However, whether a similar tropospheric temperature anomaly exists in Yaan rainfall events has not been previously discussed.

The purpose of this study is to analyze the fine-scale spatiotemporal evolution process of Yaan rainfall events and to determine the corresponding controlling three-dimensional circulation leading to and during Yaan rainfall events. Following this introduction, the data and methods are described in Sect. 2. Evolution processes of Yaan rainfall events are shown in Sect. 3. Section 4 gives the associated three-dimensional circulation and the structure of the temperature anomaly. A discussion and summary are presented in Sect. 5 .

\section{Data and methods}

The hourly rain gauge records used here are collected and quality controlled by the National Meteorological Information Center of the China Meteorological Administration. The dataset includes 5833 stations covering Sichuan Province in the warm season (May-October) of 2009-2016. Because data in year 2012 are missing at many automatic stations, data in this year are not used in this study. After quality control, 2141 stations (dots in Fig. 1a) are finally used to analyze the hourly characteristics of rainfall events over the target region. All these stations recorded more than 800 days of precipitation in the warm season of 2009-2016 (with 2012 excluded, same below).

To study the evolution process of rainfall events that affects a limited area around Yaan, we applied the method of regional rainfall event (RRE) suggested by $\mathrm{Yu}$ et al. (2015). The RRE method is suited to study the spatial-temporal evolution characteristics of rainfall processes in a specific region (Yu et al. 2015; Chen et al. 


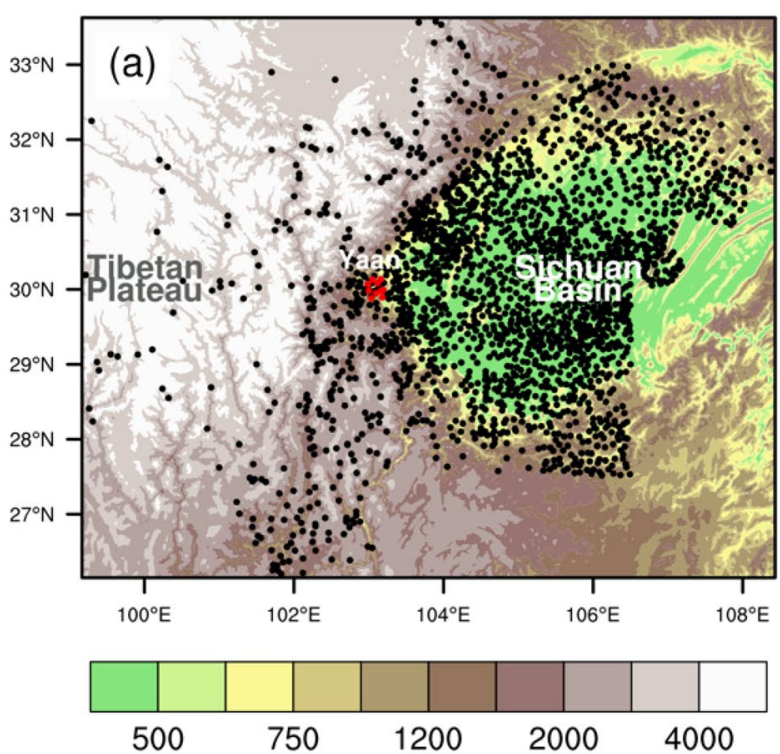

Fig. 1 Stations used in this study (a) and the multiyear warm-season average of daily precipitation amount (unit: $\mathrm{mm} \mathrm{d}^{-1}$ ) in the same region (b). There are 2141 stations in total, each of which has records of more than 800 days in the warm season (May to October) from

2017; Yuan et al. 2018). For every hour $t$, the max hourly intensity $P_{x, t}=\max \left(P_{i, t}\right)(i=1, N)$ is determined within $N$ stations in a selected key region, where $P_{i, t}$ is the measured rainfall of station $i$ at hour $t$ (here $x$ refers to the max). The time series of $P_{x, t}$ then represents the precipitation intensity of the key region, and a RRE is then defined as a period of consequent time series above the threshold with at most 1-h intermittence, following Yu et al. (2015). To remove a large number of weak rainfall events, we take $0.2 \mathrm{~mm} \mathrm{~h}^{-1}$ as the threshold. A sensitivity study with 10 different thresholds from 0.1 to $1 \mathrm{~mm} \mathrm{~h}^{-1}$ shows no significant difference of RRE's characteristics. The ratio of rainy stations in the key region to the total number of stations is defined as $\left[\left(N_{a}-1\right) /(N-1)\right]$ to quantitatively describe the spatial range of rainfall events, where $N_{a}$ and $N$ are the numbers of rainy stations and total stations in the key region respectively.

An important step of the RRE method is the selection of key stations within the key region. In this study, 10 key stations around Yaan are selected (red dots in Fig. 1a). Each station satisfies the following criteria: (a) the distance from Yaan station is smaller than $0.25^{\circ}$, (b) the elevation of the station and the average elevation of the area approximately $6 \mathrm{~km}$ around it is lower than $1200 \mathrm{~m}$, (c) the station is located in the funnel-shaped windward area east of Yaan, and (d) the station records more than 100 days of hourly precipitation without missing data in every warm season from 2009 to 2016 . The main purpose of these criteria is to ensure the coherence of the rainfall
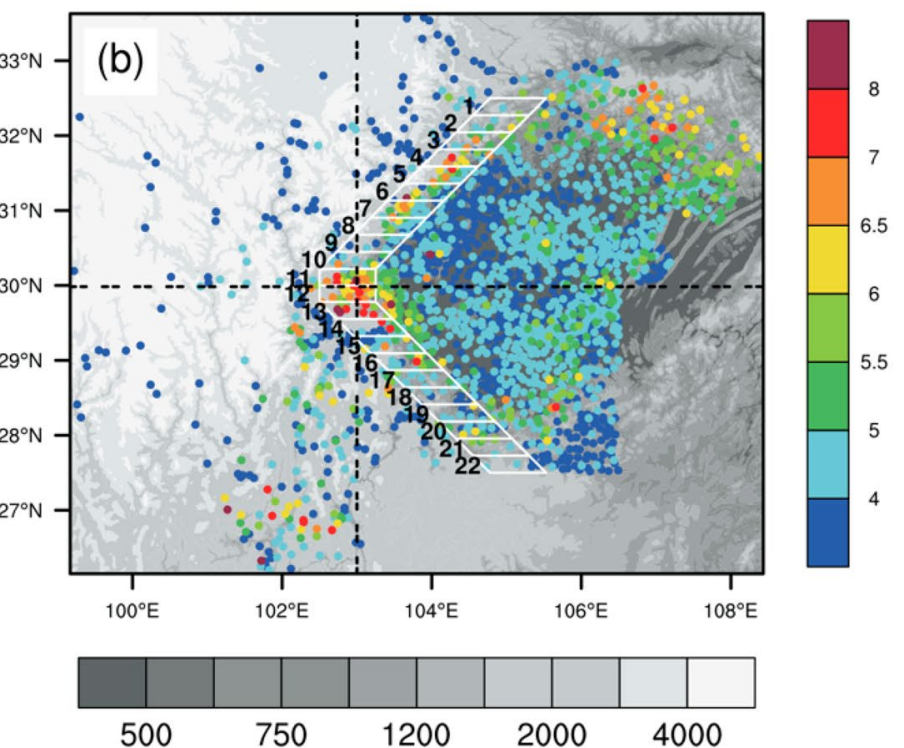

2009-2016 (with 2012 excluded). The red dots in a represent the 10 key stations around Yaan. The color shading in a and the grey shading in b represent surface elevation (unit: $\mathrm{m}$ ). The intersection of two dashed line in $\mathbf{b}$ indicates the location of Yaan station (same below)

characteristics and topography among the selected key stations.

Figure $1 \mathrm{~b}$ shows the multiyear warm-season average daily precipitation amount. Consistent with previous studies ( $\mathrm{Li}$ et al. 2010; Chen et al. 2017), more rainfall amount is found along the eastern slope of TP than over the eastern TP and western SCB. The 10 key stations are situated in the heavy rainfall center near Yaan along $30^{\circ} \mathrm{N}$ and $103^{\circ} \mathrm{E}$. Based on the 10 key stations over the Yaan region, we identified 1239 RREs in total. Figure 2a-c shows the number of RREs against mean intensity, the rainy station ratio, and the number of hours between RRE start and peak times, respectively. More than 800 RREs have mean intensities weaker than $1 \mathrm{~mm} \mathrm{~h}^{-1}$. Nearly half of the RREs have rainy station ratios of less than 0.1 , which means that they affect only 1 of the 10 key stations during the rainfall events. Figure $2 a$, b show that there are many weak and low impact RREs. The 90th percentile of the number of hours between start and peak times is $8 \mathrm{~h}$ (Fig. 2c). Figure $2 \mathrm{~d}$ shows the diurnal distribution of the start times of RREs. A major diurnal peak is found at approximately 1900 Beijing time (BJT), and more RREs start at night than during the daytime.

As we focus on high-impact RREs with high intensity, further selection for intense RREs is conducted. Based on the results above, 46 intense RREs during the warm season in 2009-2016 are selected. The criteria are as follow: (a) the maximum and mean intensity of the RRE are larger than $10 \mathrm{~mm} \mathrm{~h}^{-1}$ and $1 \mathrm{~mm} \mathrm{~h}^{-1}$, respectively, both of which exceed approximately the 70th percentile to ensure the intensity of 

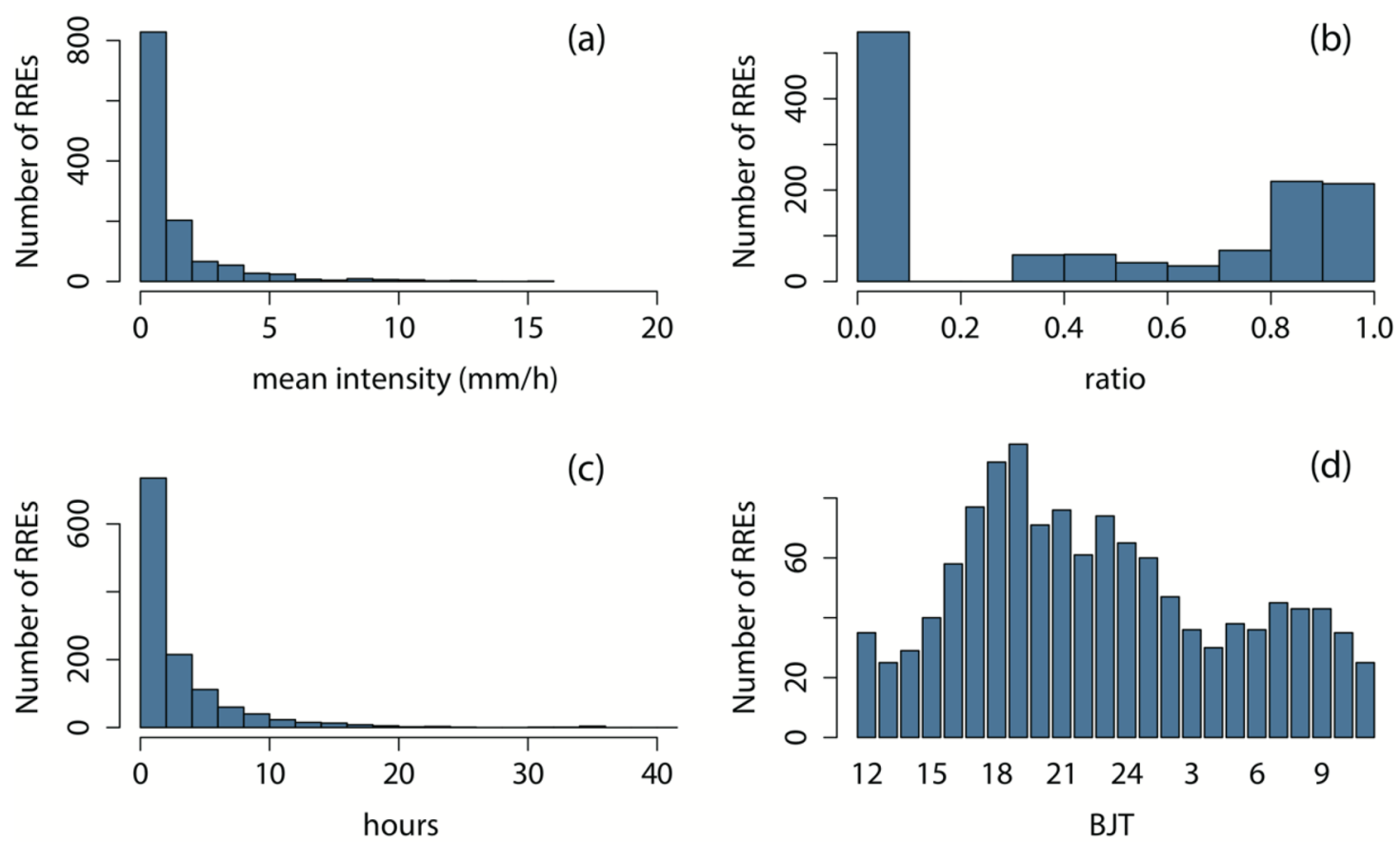

Fig. 2 Distributions of the number of RREs against mean intensity (a), rainy station ratio (b), and the number of hours from start to peak time (c), and the diurnal distribution of the start time of the RREs (d)

the RRE; (b) the rainy station ratio is larger than 0.3 , which means at least 4 out of 10 key stations are affected during the RRE; (c) the number of hours between the start and peak times is less than $8 \mathrm{~h}$ (90th percentile); and (d) the start time of the RRE is between 1700 BJT and 2100 BJT. The criteria (c) is to exclude those extremely abnormal RREs whose peak hour is far beyond the start hour. And criteria (d) is set to concentrate the start time of the RREs under the consideration that the mechanisms of rainfall events start at different hour during the day may be different. The values of the parameters in these criteria, such as the $10 \mathrm{~mm} \mathrm{~h}^{-1}$ max intensity and 0.3 rainy station ratio, were changed and tested, and no significant difference to our results was found.

Series reanalysis products (e.g., ERA-40 and ERAInterim) from the European Centre for Medium-Range Weather Forecasts (ECMWF) had been evaluated and widely used to represent the circulation conditions over the TP and surrounding areas, by which lots of meaningful results has been gained (see, among others, Wang and Zeng 2012; Bao and Zhang 2013; Lin 2015). To analyze the three-dimensional circulation associated with the evolution process of rainfall events, the latest hourly ERA5 reanalysis, which is carried out by ECMWF and developed through the Copernicus Climate Change Service (C3S 2017), is used (Hersbach and Dee 2016; Hersbach et al. 2019). The dataset used here has a horizontal resolution of $0.25^{\circ} \times 0.25^{\circ}$ and contains 27 (out of 37 original) vertical levels covering April-November from 2009 to 2016. Due to the long-time span of the warm season, the anomalous circulation is composited and analyzed to avoid intraseasonal and diurnal variability by removing the multiyear mean of the corresponding time steps for 11 days around the analyzed time step.

\section{Characteristics and evolution process of Yaan intense RREs}

Following Yuan et al. (2018), we divide the rainfall process of intense RREs into 4 periods to investigate the evolution characteristics: $3 \mathrm{~h}$ before the start of RREs, from start to peak time, from peak to end time, and from end time to $3 \mathrm{~h}$ later. Figures 3 and 4 show the average hourly rainfall amount and frequency of these four periods respectively. Rainfall frequency at a time step is defined as the ratio of rainy hours to non-missing hours of corresponding time step in all the intense RREs. More stations with larger rainfall amounts are found over the northeastern side of the key region $3 \mathrm{~h}$ before the RRE start (Fig. 3a), partly due to relatively larger precipitation frequencies (Fig. 4a) in the same area at the same time. From the start to peak hour, the rainfall amount over the key region increases to the local maximum, which exceeds $1.7 \mathrm{~mm} \mathrm{~h}^{-1}$. The main rain belt lies along the eastern slope of TP. The precipitation frequency shows a pattern similar to that of the rainfall amount in the same period, exceeding 50\% at many stations. In the second half (from peak to end time) of the RREs, the 

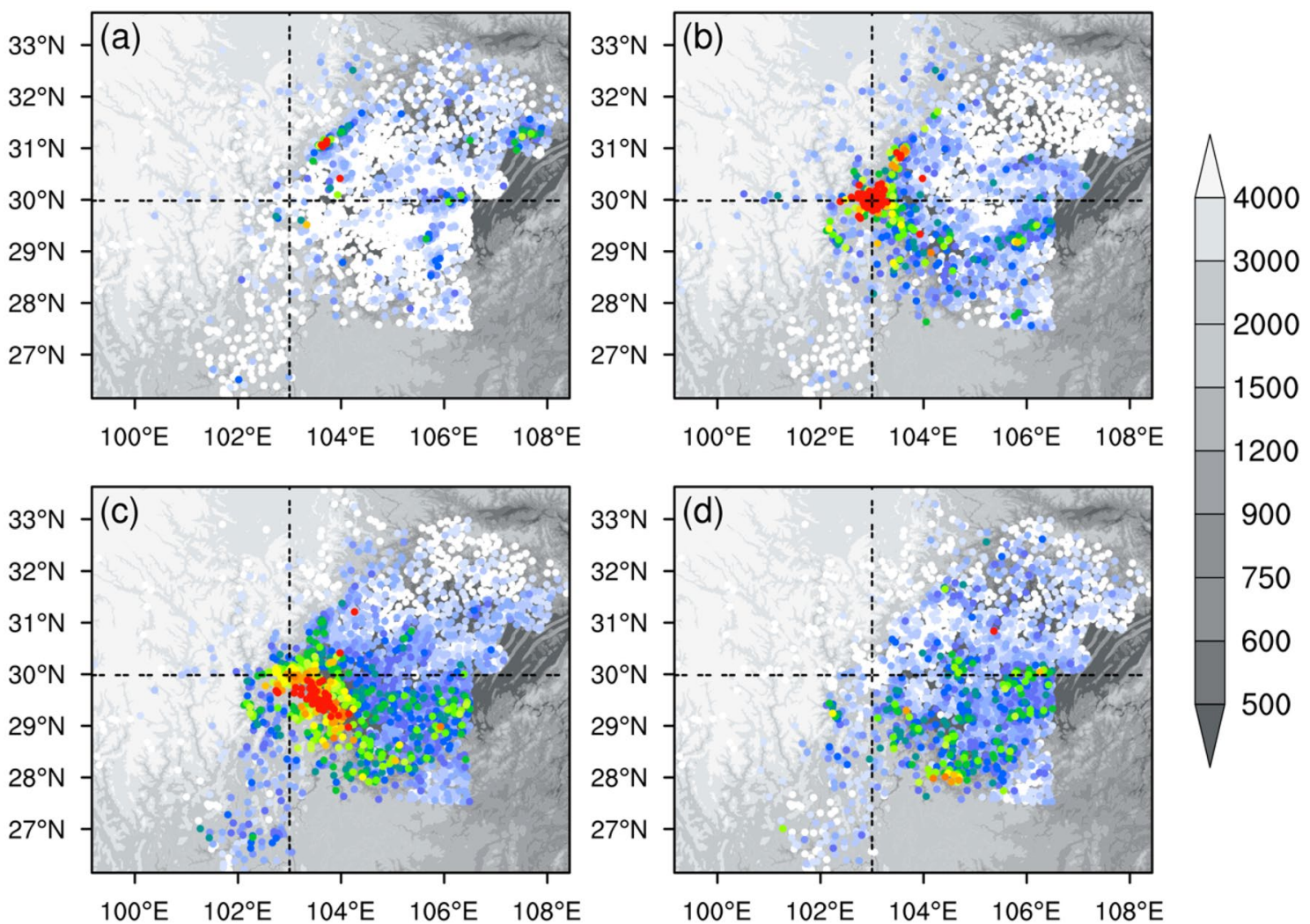

900

750

600

500

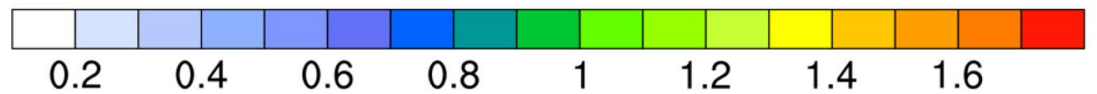

Fig. 3 Average rainfall amounts (unit: $\mathrm{mm} \mathrm{h}^{-1}$ ) in four periods of RREs: $\mathbf{a} 3 \mathrm{~h}$ before RRE start, $\mathbf{b}$ from start to peak time, $\mathbf{c}$ from peak to end time, and $\mathbf{d} 3 \mathrm{~h}$ after end time. The grey shading represents surface elevation (unit: $\mathrm{m}$ )

rainfall amount in the key region slightly decreases, while the rainfall amount over the south and southeast of the key region increases. The average rainfall amount from the peak to end time is smaller than that from the start to peak time in the key region, which is similar to the evolution of the warm-season strong RREs over the plain area of Beijing City (Yuan et al. 2018). The precipitation frequency also propagates southeastward. Meanwhile, the spatial range of rainfall amount and frequency expands. After the end of the RREs, the hourly rainfall amount and frequency in the key region are below $0.2 \mathrm{~mm} \mathrm{~h}^{-1}$ and $10 \%$, respectively. Rainfall then moves further south and east.

From the above results, we find that on average, there was a relatively higher frequency of rainfall occurring over the northeast of the key region several hours prior to the start of the Yaan RREs. After the RREs ended, rainfall tended to propagate to the south and east. To investigate the evolution process of Yaan RREs hour by hour, we divide the eastern periphery of TP into 22 subregions (white boxes in Fig. 1b). For each subregion, we calculate the anomalous rainfall amount at each hour from $12 \mathrm{~h}$ before to $12 \mathrm{~h}$ after the RREs start. Note that the subregions are numbered north to south from 1 to 22 . The rainfall amount anomaly shows a propagation tendency with time from the northern subregion to the southern subregion (Fig. 5). Before the RRE start, there is nearly no anomalous rainfall amount in the key region (within subregions 11 and 12) or the southern subregions. A moderate amount of anomalous rainfall is found in the northern subregions prior to the Yaan RREs. When the RREs start, the rainfall amount anomaly in the key region increases rapidly and reaches a maximum (exceeds $2.6 \mathrm{~mm} \mathrm{~h}^{-1}$ ) a few hours later. The large rainfall amount anomaly in the key region lasts for approximately $6 \mathrm{~h}$, during which rainfall begins to move southeastward. The asymmetry of the evolution of the precipitation amount in Yaan is in good agreement with the previous study (Yu et al. 2013). From the key region toward the south, the precipitation amount gradually decreases. 

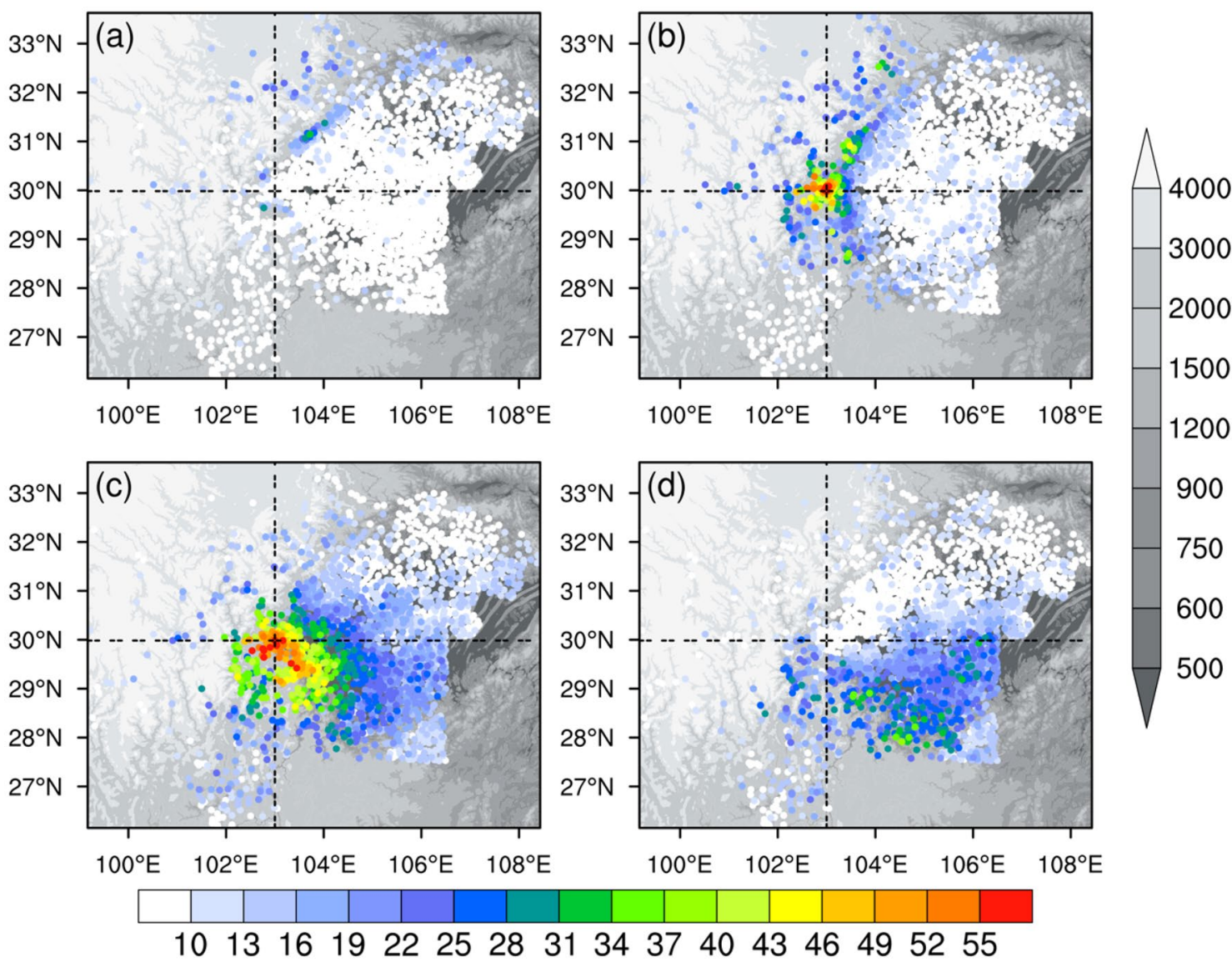

Fig. 4 Same as that in Fig. 3, but for rainfall frequency (unit: \%)

\section{Three-dimensional circulation corresponding to the Yaan intense RREs}

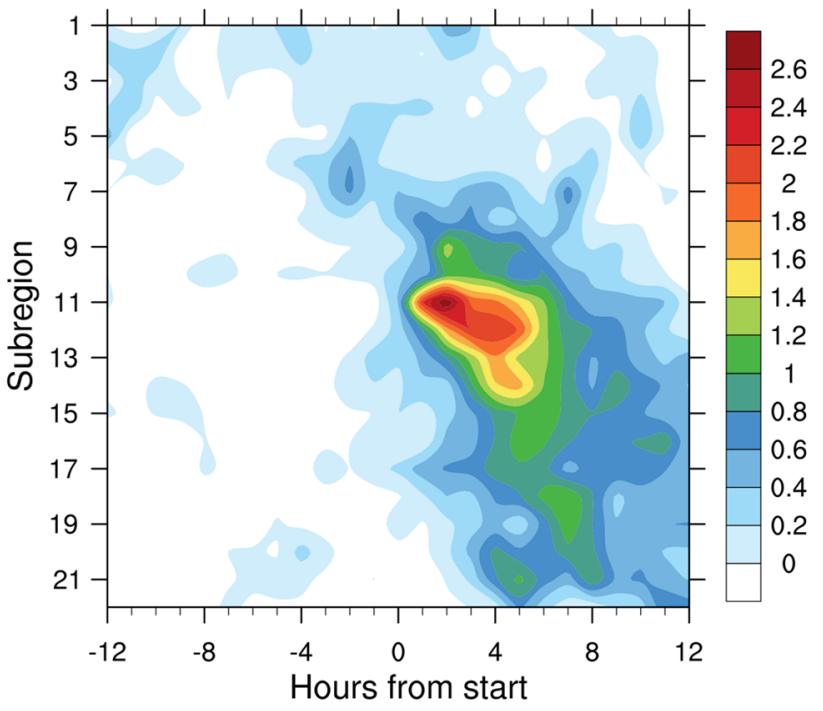

Fig. 5 Anomalous rainfall amount (unit: $\mathrm{mm} \mathrm{h}^{-1}$ ) averaged in each of the 22 subregions at $12 \mathrm{~h}$ around the start time of the RREs. The 22 subregions are shown in Fig. 1b

\subsection{Anomalous tropospheric circulations before intense RREs at Yaan}

We first examine the atmospheric circulations at $3 \mathrm{~h}$ before the RREs start. In the upper troposphere $(300 \mathrm{hPa})$, there are a synoptic-scale ridge and a synoptic-scale trough at high latitudes (Fig. 6a). Associated with this synoptic-scale wave is an anomalous warm belt along $35^{\circ} \mathrm{N}$ from the west of TP to the east of North China with the warm center at approximately $40^{\circ} \mathrm{N}, 112^{\circ} \mathrm{E}$. Driven by hydrostatic and geostrophic equilibriums, a warm anomaly would elevate the geopotential height above it. Associated with synoptic wave, there is an anomalous northeast-southwest oriented divergent belt at $200 \mathrm{hPa}$ extending from the east of TP to the North China. The center of the upper-level divergent center is located in the north and northwest of the Yaan region. An anomalous relative vorticity center at $500 \mathrm{hPa}$ is also located in north of Yaan (Fig. 6b).

The upper tropospheric synoptic-scale wave is accompanied by a broad and deep trough in central China and a ridge 

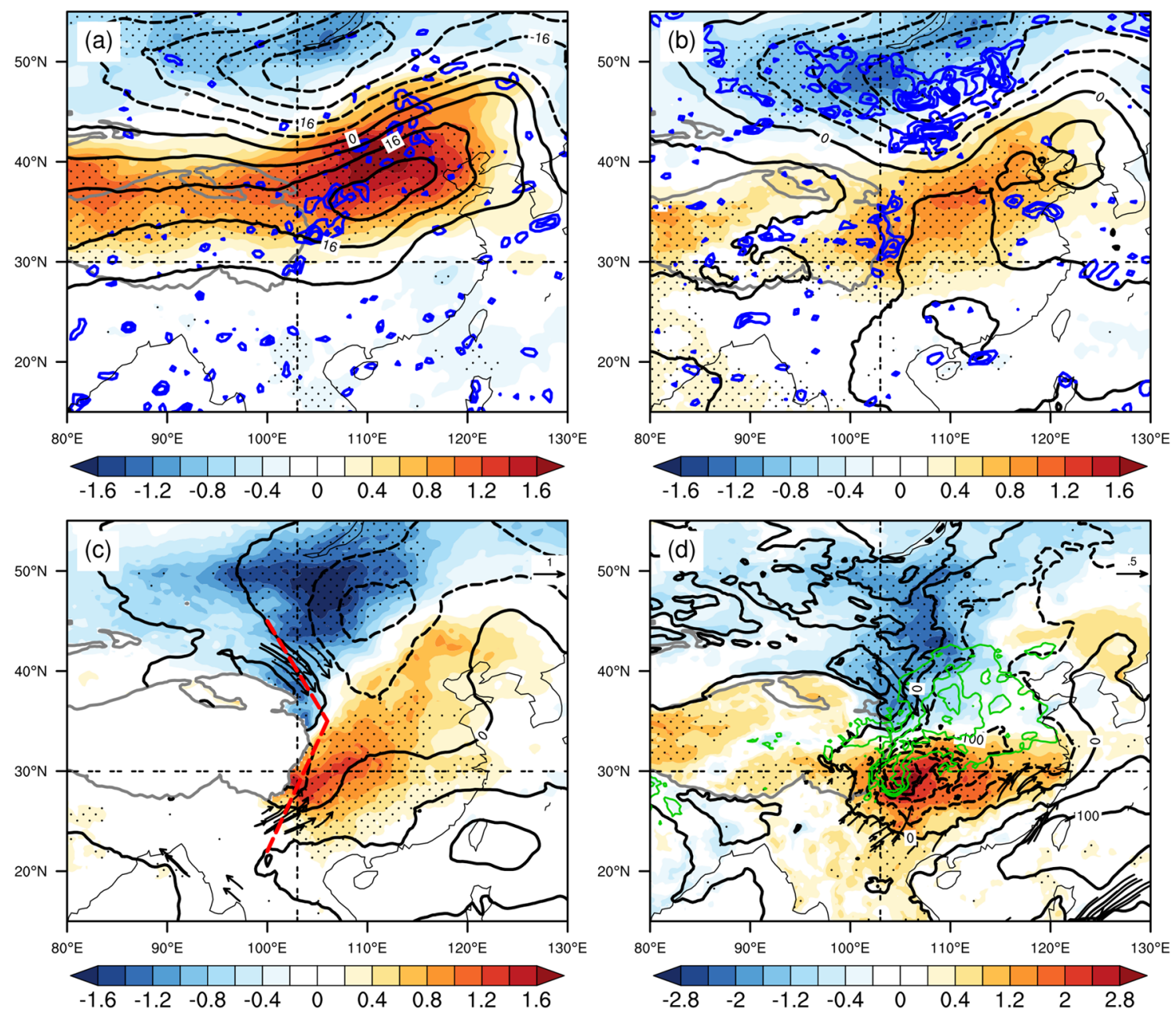

Fig. 6 Anomalous circulations and thermodynamic properties from the upper troposphere to surface at $3 \mathrm{~h}$ before the Yaan intense RREs develop. a Temperature (shaded, unit: $\mathrm{K}$ ) and geopotential height (black contour, unit: gpm) at $300 \mathrm{hPa}$, divergence (blue contour, start from 0.8 , interval 0.5 , unit: $10^{-5} \mathrm{~s}^{-1}$ ) at $200 \mathrm{hPa}$; b temperature, geopotential height and relative vorticity (blue contour, start from 0.8 ,

to the east at $700 \mathrm{hPa}$ level (Fig. 6c). The cyclonic anomaly associated with the trough extends southwestward to the $\mathrm{SCB}$. At the southern tip of the trough is a mesoscale negative center of geopotential height. This negative perturbation of geopotential height has been reported in a previous study (Peng et al. 1994). At the $700 \mathrm{hPa}$ level, a positive anomaly of geopotential height extends from the subtropics at approximately $20^{\circ} \mathrm{N}$ to northeastern China, which strengthens the subtropical high in the northwestern Pacific. While it is not clear whether this strengthening is caused by the synopticscale ridge, the positive anomaly of geopotential height in the subtropics enhances the low-level southwesterly, which transports moisture to the SCB to feed the intense rainfall.

At the surface (Fig. 6d), the region to the south of the SCB is under the influence of southwesterly. Warm advection by the southwesterly and downslope winds lead to warm

interval 0.5 , unit: $10^{-5} \mathrm{~s}^{-1}$ ) at $500 \mathrm{hPa}$; c temperature, geopotential height and winds (vector, unit: $\mathrm{m} \mathrm{s}^{-1}$, only significant at the $10 \%$ level of student $t$ test are shown) at $700 \mathrm{hPa}$; d surface pressure (black contour, unit: $\mathrm{Pa}$ ), temperature and specific humidity (green contour, start from 0.8 , interval 0.4 , unit: $\mathrm{g} \mathrm{kg}^{-1}$ ). Dot shading indicates the temperature which are significant at the $10 \%$ level of Student $t$ test

anomaly center in the SCB as well as its downstream area. A low-pressure perturbation is collocated with the mesoscale low at the $700 \mathrm{hPa}$ level. The anomalous cold northwesterly behind the trough confronts the warm and wet southwesterly from lower latitudes at the north of the key region, resulting in wind convergence in the northwestern SCB.

Figure 7 shows cross sections along the oblique line which approximately fit the topography (red line shown in Fig. 6c) at $3 \mathrm{~h}$ prior to the Yaan intense RREs start. An obvious tilted tropospheric warm anomaly can be found with its main body extending from the surface at approximately $30^{\circ}$ $\mathrm{N}$ to the upper troposphere at approximately $45^{\circ} \mathrm{N}$. Cold anomalies are located to the north of the warm anomaly. This resembles the typical thermodynamic structure of a frontal system associated with a synoptic wave. There is a positive geopotential height anomaly above the warm anomaly in the 


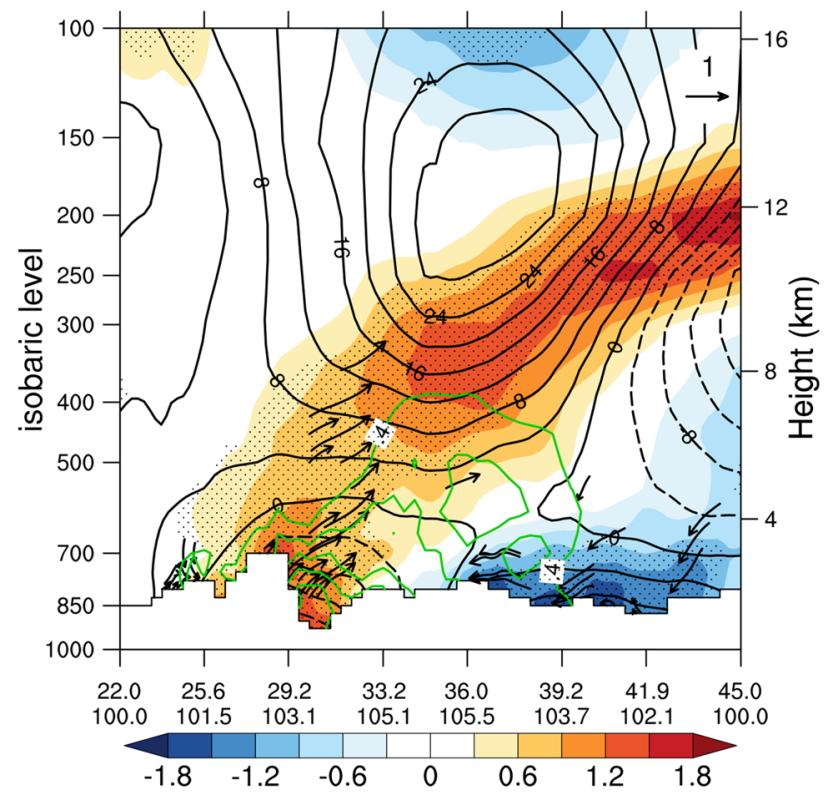

Fig. 7 Cross section along the oblique red line shown in Fig. 6c of anomalous temperature (shaded, unit: K), geopotential height (black contour, unit: gpm), water vapor (green contour, unit: $\mathrm{g} \mathrm{kg}^{-1}$, start from 0.4, interval 0.4), and winds (vector, $\mathrm{v}$ component unit: $\mathrm{m} \mathrm{s}^{-1}$, vertical winds unit: $-10^{-2} \mathrm{~Pa} \mathrm{~s}^{-1}$, only significant at the $10 \%$ level of Student $t$ test are shown) at $3 \mathrm{~h}$ prior to RREs start. Dot shading indicates the temperature which are significant at the $10 \%$ level of Student $t$ test

middle and high latitudes. An anomalous meridional lifting branch can be found over the SCB at approximately $30^{\circ} \mathrm{N}$, with the significant anomalous northerly intruding to the northern SCB. The upward motion brings the moisture to upper-level and favors the northern rainfall prior to the Yaan intense RREs.

Therefore, prior to RREs at Yaan, the atmospheric condition has two key features that favor intense rainfall. One is the enhanced southwesterly from the south and southeast; the second is the approaching synoptic wave from the northwest. The southwesterly brings moisture to the SCB east of Yaan; the approaching wave creates a lower tropospheric trough in northern China that extends to the region near Yaan, forming a mesoscale low-pressure center. The northwesterly behind the trough and the southwesterly in front of it converge in the SCB region, causing upward motion and rainfall.

\subsection{Evolution of the anomalous tropospheric circulations corresponding to the rainfall process}

We next investigate the evolution of anomalous circulation that results in the evolution process of rainfall events. The circulation features are presented at $-9 \mathrm{~h},-6 \mathrm{~h},-3 \mathrm{~h}$ of the
RREs start, and at their start, peak and end time. The warm anomaly in the upper troposphere moves southeastward during these time steps (Fig. 8). At $-9 \mathrm{~h}$ before the start time, the main warm center associated with the synoptic wave is located at approximately $105^{\circ} \mathrm{E}$ and beyond $40^{\circ} \mathrm{N}$ at $300 \mathrm{hPa}$. In the following several steps, the anomalous warm center moves eastward and southward, corresponding to the southeastward propagation of the synoptic wave. The anomalous divergent region experiences a southeastward movement and intensifies at $3 \mathrm{~h}$ prior to the start time. Meanwhile, an anomalous relative vorticity center at $500 \mathrm{hPa}$ is located over the northeastern TP at $9 \mathrm{~h}$ prior. This anomalous vortex is at the southern edge of the trough. It moves southeastward together with the high-level warm and divergent anomaly to the SCB and merges with the vorticity anomaly in the SCB that corresponds to the mesoscale low discussed before. At $3 \mathrm{~h}$ before the Yaan RREs develop, the intensified divergent anomaly center and positive vorticity anomaly center are located immediately north of and over the key region, providing favorable high-middle level conditions for the northern rainfall. At the peak time, the key region is covered by both upper-level divergent and mid-level vorticity anomalies. These two anomalies propagate southeastward and decrease at the end of RREs.

The time evolution of the wind and temperature anomalies at the $700 \mathrm{hPa}$ is shown in Fig. 9. A lower-tropospheric warm anomaly center over the eastern slope of TP and an anomalous cyclonic center at approximately $33^{\circ} \mathrm{N}, 104^{\circ} \mathrm{E}$ can be found at $9 \mathrm{~h}$ before the start time of the Yaan RREs (Fig. 9a). In the following several time steps, the cold northerly from the rear of the anomalous cyclone intrudes southward as the anomalous cyclone moves southeastward, and the warm center moves southward along the eastern slope of TP and vanishes. The boundary of the warm and cold temperature anomalies is located on the northeastern slope of $\mathrm{TP}$ at $9 \mathrm{~h}$ prior. Most part of SCB is controlled by significant southwesterly. As the temperature boundary moves southward in the following time steps, the southwesterly retreats to the south of SCB, favoring the moisture transportation to Yaan. The negative geopotential height intensifies and expands at the start and peak time of RREs, providing benefit low-level convergence condition. At the end of RREs, the warm anomaly, the anomalous southwesterly and the negative geopotential center decrease with the cold wind intruding from the north.

The time evolution of circulation features at the surface is similar to that at the $700 \mathrm{hPa}$ (Fig. 10). At $9 \mathrm{~h}$ before the Yaan RREs start, the south and east of the SCB are dominated by anomalous southerly, and the front of the significant northerly is located along $37^{\circ} \mathrm{N}$. An anomalous warm low-pressure center exists in the SCB. As the anomalous southeasterly blows to the northern part of the eastern slope of TP, there is a wet center over the northern SCB, 

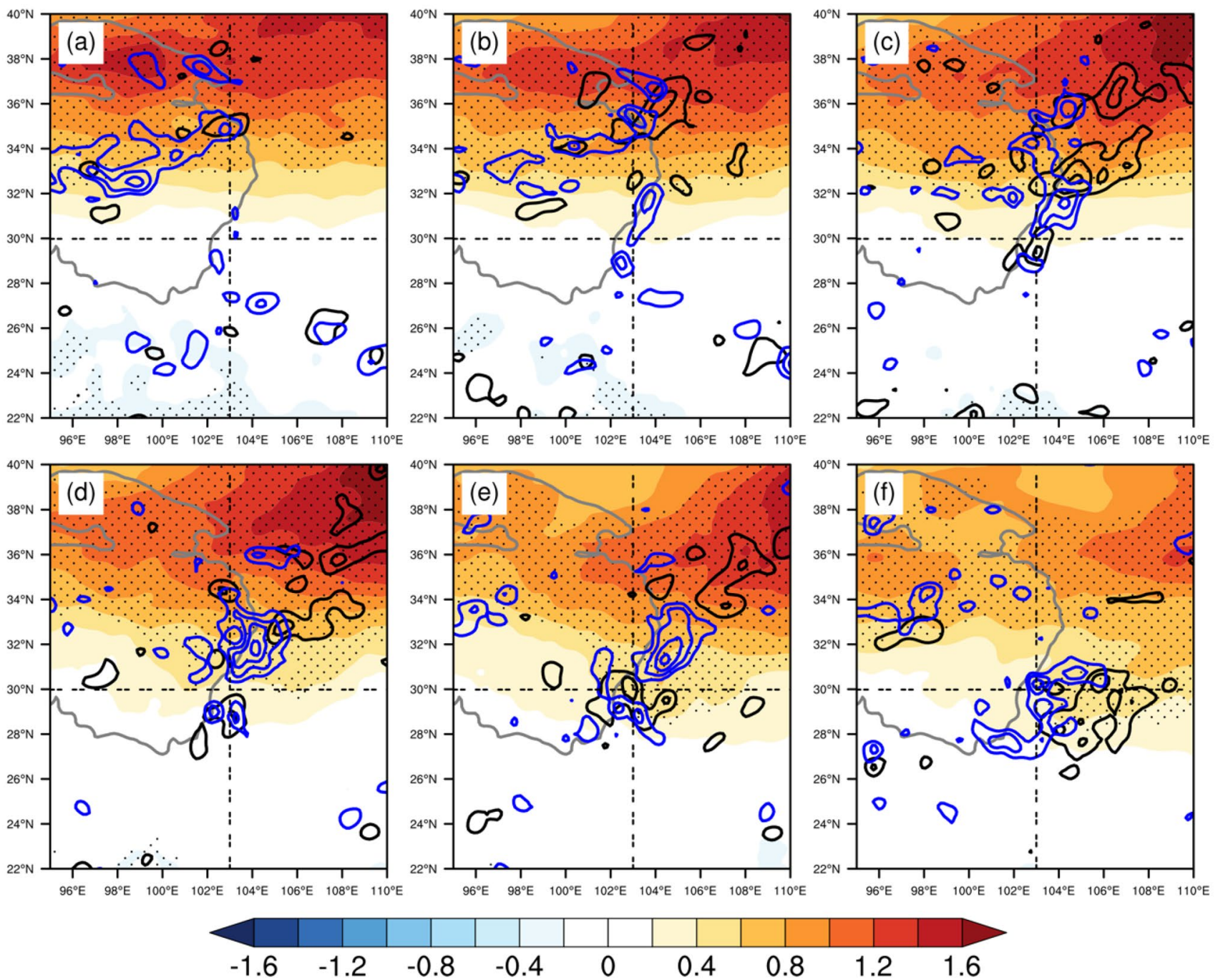

Fig. 8 Anomalous temperature at $300 \mathrm{hPa}$ (shaded, unit: K), divergence at $200 \mathrm{hPa}$ (black contour, unit: $10^{-5} \mathrm{~s}^{-1}$, start from 0.8 , interval 0.5 ) and relative vorticity at $500 \mathrm{hPa}$ (blue contour, unit: $10^{-5}$ $\mathrm{s}^{-1}$, start from 0.8, interval 0.5) at different time steps (a-f represents
$-9 \mathrm{~h},-6 \mathrm{~h},-3 \mathrm{~h}$ of the RREs start, and the start, peak and end time, respectively). The gray contour indicates the $3000 \mathrm{~m}$ surface elevation, and the dot shading indicate the temperature which are significant at the $10 \%$ level of Student $t$ test favoring the northern rainfall. In the following two steps, an enhancement of the vortex can be seen as the central pressure decreases. And the southerly intensifies, and the warm center gets warmer. At the start time, the northerly intrudes into the SCB along the eastern slope of TP and the wet center is closer to Yaan relative to several hours prior. At the end time, the anomalous northerly takes over the SCB, the temperature thus decreases, and the anomalous warm vortex weakens and moves southeastward.

With the above discussions, we can explain the time evolution of the RREs previously shown in Figs. 3, 4 and 5. Prior to the RREs at Yaan, low-level winds in the key region are southerly. The low-level anomalous air flow converges toward topography to the north of Yaan and favors northern rainfall (Fig. 11a). As the anomalous trough approaches, upper level divergence leads to the decrease of surface pressure and geopotential height to the northwest of Yaan. This causes the southerly to rotate to southeasterly (Fig. 11b) and rainfall to form near Yaan, corresponding to the start of the Yaan RREs. As the trough and the associated low-pressure anomaly propagate further southeastward, winds near Yaan at the peak time become the easterly which is larger than that at the start time. The easterly converges toward the windward slope and funnel-shaped topography perpendicularly, creating the largest slope-perpendicular wind component, and corresponding to the rainfall center at peak hour (Fig. 11c). Further southeastward propagation of the trough leads to weakening of the easterly and southeastward spreading of the rain area, corresponding to the end of the RREs. During the evolution, the $750 \mathrm{hPa}$ wind over Yaan experiences 

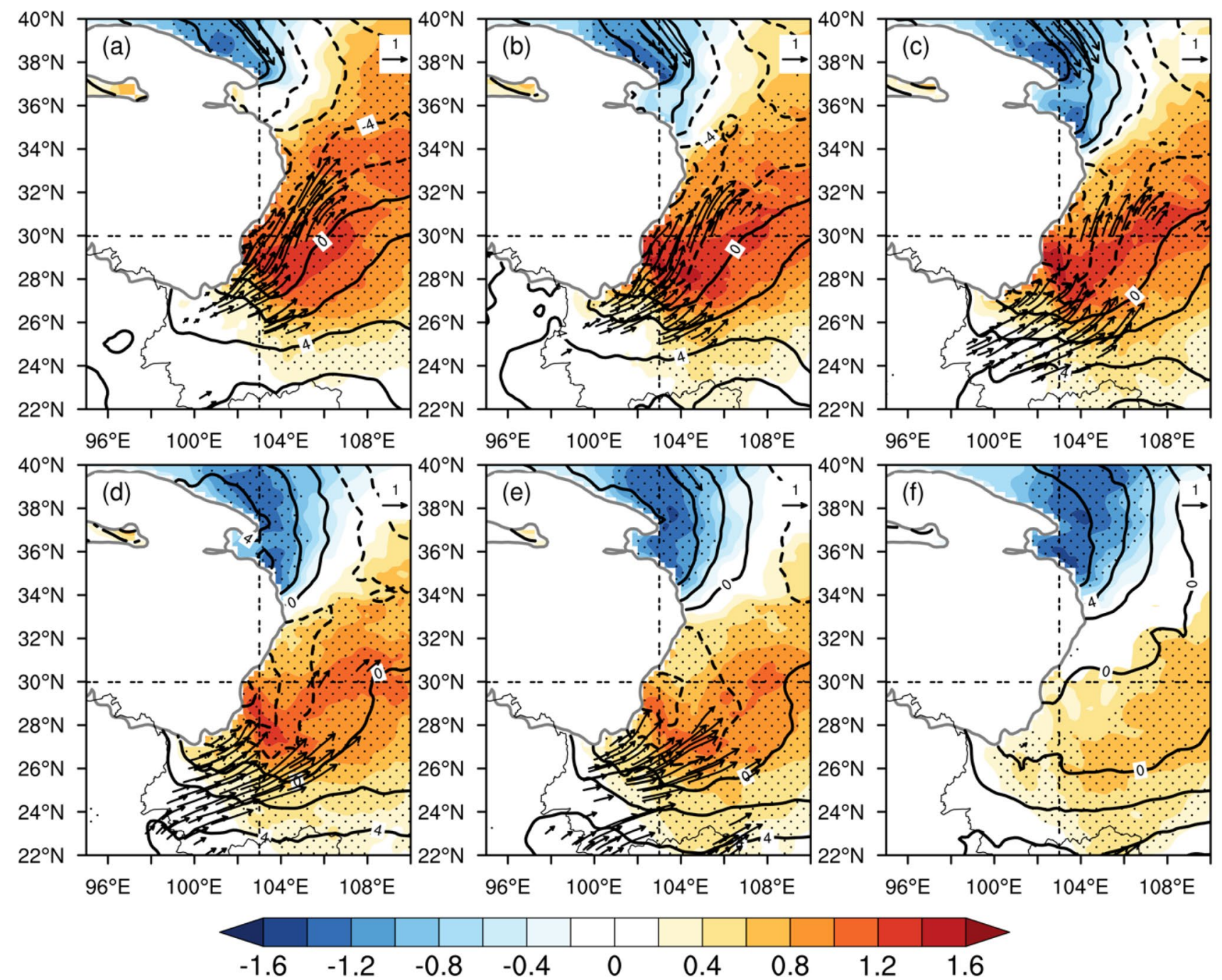

Fig. 9 Same as that in Fig. 8, but for anomalous temperature (shaded, unit: K), geopotential height (black contour, unit: gpm) and winds (vector, unit: $\mathrm{m} \mathrm{s}^{-1}$, only significant at the $10 \%$ level of Student $t$ test are shown) at $700 \mathrm{hPa}$

a counter-clockwise rotation, whose angle with the terrain explains the rainfall distributions in Figs. 3, 4 and 5.

We use the Hovmueller diagram to more clearly show the role of the synoptic wave and associated upper level forcing on the lower-tropospheric circulation. A clear eastward propagation of upper-level divergence and warm anomalies as well as mid-level vorticity anomaly can be found (Fig. 12a). At $9 \mathrm{~h}$ prior, the upper-level divergence are located in the west. When the RREs start, the anomalous divergent and vorticity centers move to just north of Yaan. The southward progression of lower tropospheric circulation is shown in Fig. 12b. At the surface, a southward intrusion of the cold anomaly can be found before the start time. The wind anomaly at $750 \mathrm{hPa}$ near the key region shows an obvious counter-clockwise rotation during these time steps. The change in the wind direction in the SCB, as pointed out earlier, is closely connected with the intrusion of the cold northerly.
The anomalous southerly during -9 to $-6 \mathrm{~h}$ blows to the northern terrain and results in the northern large vertical velocity at $700 \mathrm{hPa}$ at around $35^{\circ} \mathrm{N}$. As the winds rotate toward the right west of the slope, an even larger vertical velocity appears at the middle part of the eastern slope of TP, i.e., the Yaan region at the start hour. These changes in the location and intensity of dynamic conditions explain the southward movement and intensity evolution of the rainfall amounts of the Yaan intense RREs.

\section{Conclusions and discussion}

Hourly rain gauge data and new hourly ERA5 reanalysis are used to investigate the evolution process of warm season intense RREs in Yaan and their associated three-dimensional circulations. The statistical characteristics of the Yaan RREs 

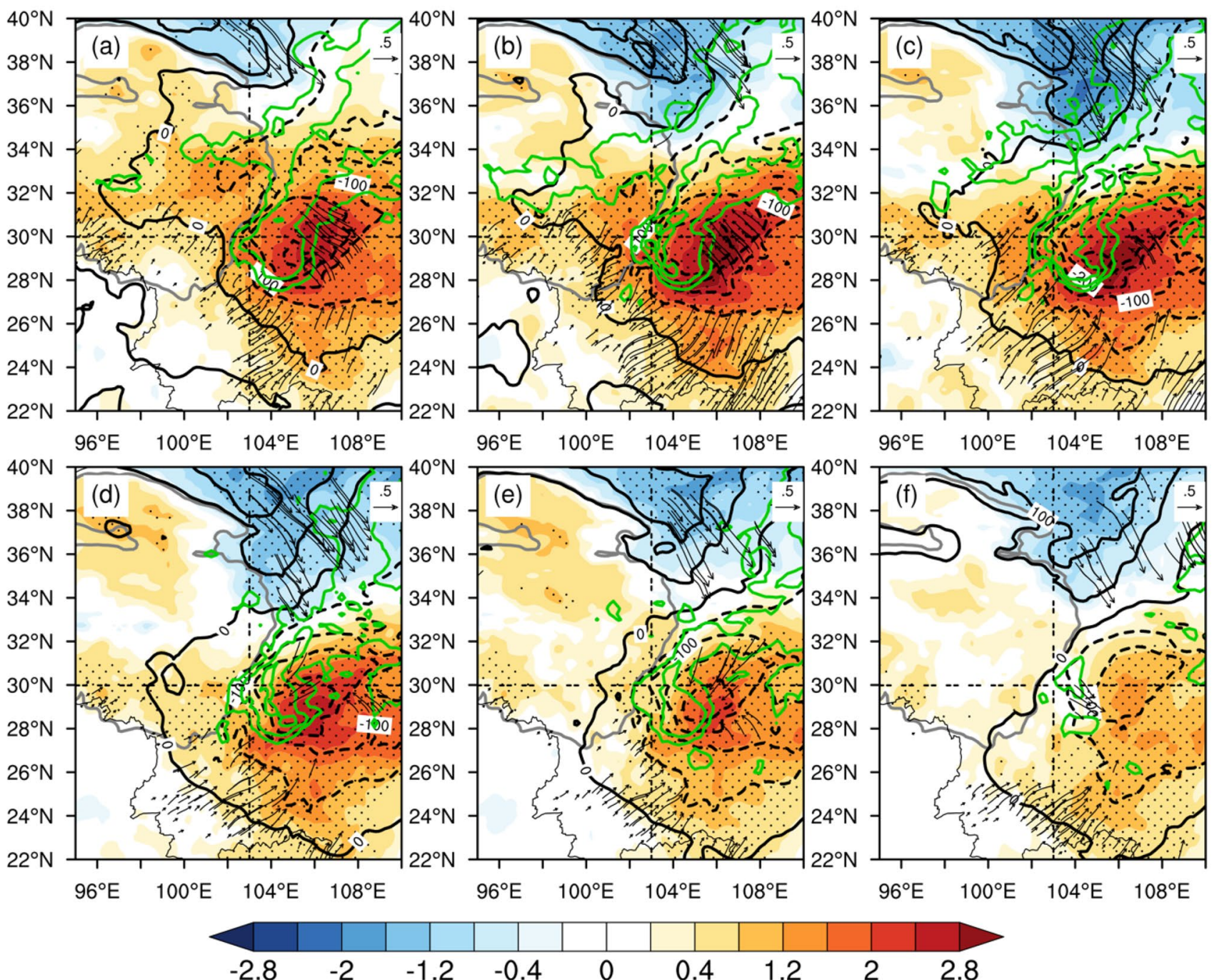

Fig. 10 Same as that in Fig. 8, but for anomalous surface pressure (black contour, unit: Pa), temperature (shaded, unit: K), winds (black vector, unit: $\mathrm{m} \mathrm{s}^{-1}$, only significant at the $10 \%$ level of Student $t$ test are shown) and water vapor (green contour, unit: $\mathrm{g} \mathrm{kg}^{-1}$, start from 0.8 , interval 0.5$)$ at the surface

wave creates a lower tropospheric trough in northern China that extends to the region near Yaan, forming a mesoscale low-pressure center. The northwesterly behind the trough and the southwesterly in front of it converge in the SCB region, causing upward motion and rainfall. The anomalous low-level southwesterly enhances moisture transport to the SCB.

3. The evolution of the Yaan intense rainfall process is closely related to the intrusion of the anomalous lowlevel wind associated with the surface low pressure center and the middle level trough of the synoptic scale wave. It is the interaction of the anomalous low-level wind and the topography that causes the particular progression of RREs in Yaan: Before the start of Yaan rainfall, the anomalous cold air underneath the tropospheric warm anomaly is located to the northwest of

2. A rainfall-favorable circulation is found when the Yaan intense RREs are to start. An upper-level synoptic-scale 
Fig. 11 Winds at $750 \mathrm{hPa}$ (vector, unit: $\mathrm{m} \mathrm{s}^{-1}$ ) and their perpendicular component toward terrain (black contour, unit: $\mathrm{m} \mathrm{s}^{-1}$ ), and precipitation frequency (color dots, unit: \%) at $-3 \mathrm{~h}$ of RREs start (a), and at the start (b), peak (c), and end time (d). The grey contours represent surface elevation (unit: m, 500, 1500 and $2500 \mathrm{~m}$ contour are drawn)
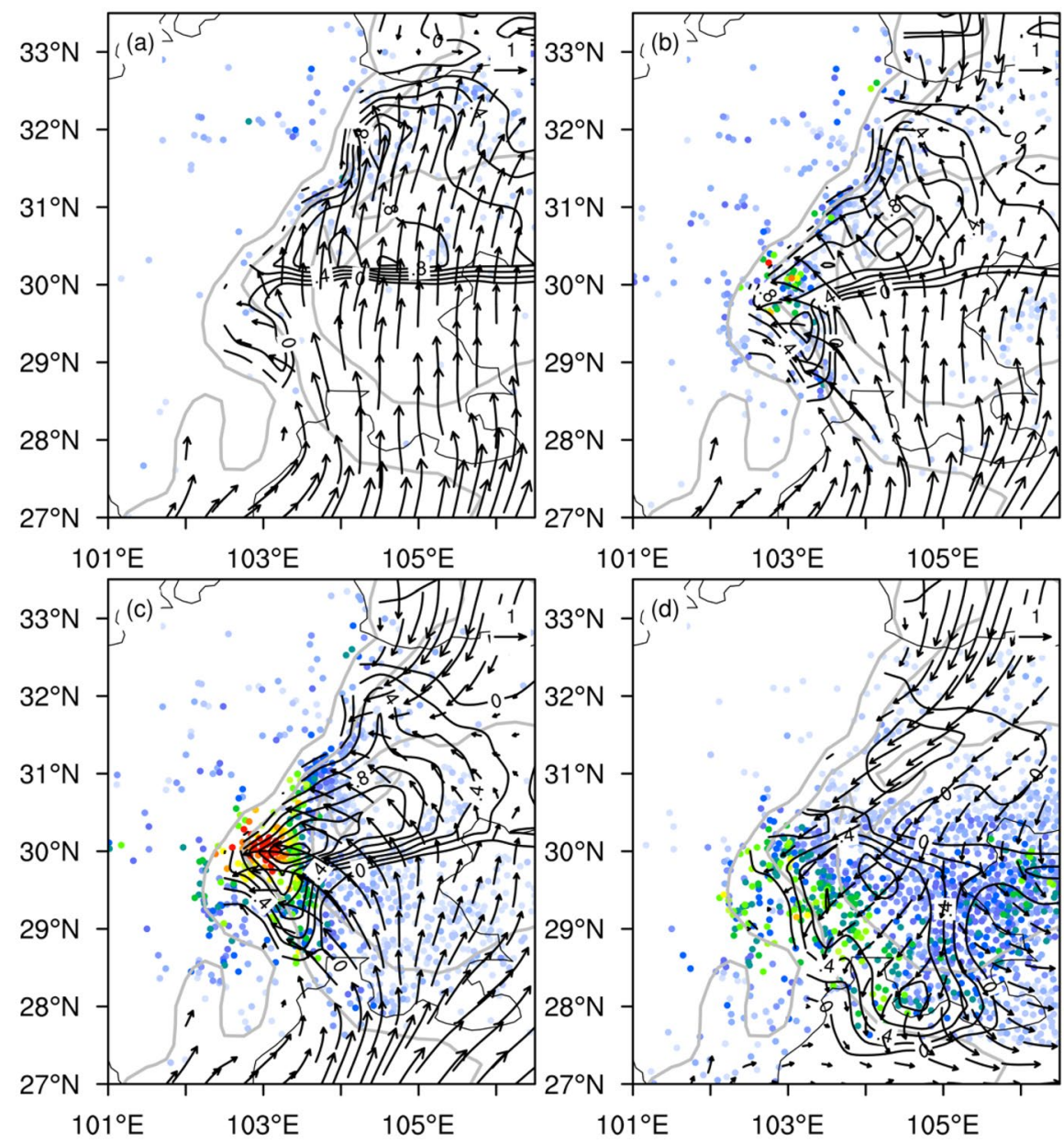

55 52 49 46 40 37 34 1 28 25 22 9 (6) 13

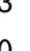
0

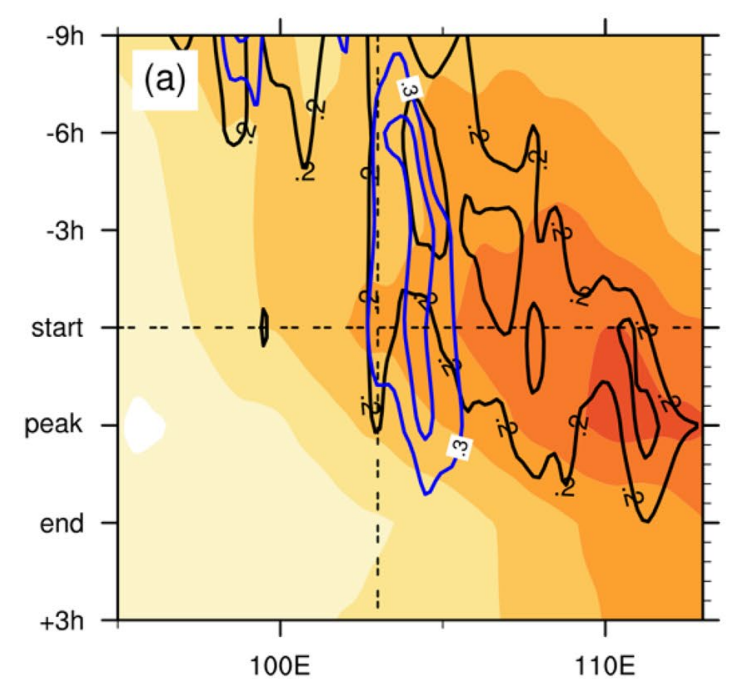

Fig. 12 a Hovmueller plot for anomalous temperature at $300 \mathrm{hPa}$ (shaded, unit: K), divergence at $200 \mathrm{hPa}$ (black contour, unit: $10^{-5} \mathrm{~s}^{-1}$ ) and relative vorticity at $500 \mathrm{hPa}$ (blue contour, unit: $10^{-5} \mathrm{~s}^{-1}$ ) averaged between $30^{\circ} \mathrm{N}$ and $40^{\circ} \mathrm{N}$; b the temporal evo-

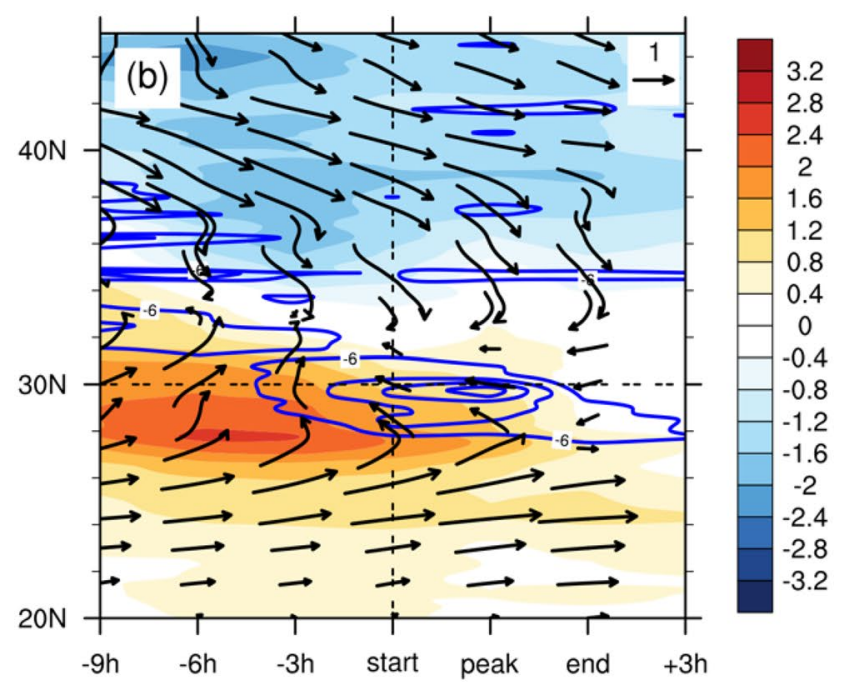

lution of anomalous surface temperature (shaded, unit: K), $700 \mathrm{hPa}$ vertical velocity (blue contour, unit: $-10^{-2} \mathrm{~Pa} \mathrm{~s}^{-1}$ ), and $750 \mathrm{hPa}$ horizontal winds (vector, unit: $\mathrm{m} \mathrm{s}^{-1}$ ) at different latitudes averaged between $103^{\circ} \mathrm{E}$ and $105^{\circ} \mathrm{E}$ 
Yaan. Lower-tropospheric wind is southwesterly over Yaan, which causes weak precipitation over the north slope. When the cold air moves southeastward and the surface lower pressure intensifies, Yaan experiences a counter-clockwise wind rotation, from southwesterly to southerly and then easterly. It is the easterly phase, with wind convergence perpendicularly upslope the terrain, that corresponds to the peak RREs.

Based on the limited rain gauge data available, the overall evolution characteristics of precipitation processes revealed in this study are imperfect to a certain degree. There is a significant decrease in the number of stations from the SCB to the eastern TP. The rainfall process, especially those from the plateau, could hardly be captured by the station network. In addition, different phases of precipitation could appear over the mountains and may not be fully recorded by rain gauges. Therefore, additional datasets, including satellite and radar products, are needed to further study the characteristics of different kinds of Yaan RREs. The precipitation around Yaan and associated circulations are affected by multiscale orography. There is the large-scale TP in the west, the relatively smaller scale SCB in the east, and the even smaller scale terrains on the eastern periphery of TP. These orographic features could have different thermal and dynamical effects on the circulations at different levels under different conditions. Topography may also influence the microphysics in clouds that directly form the raindrops. Our findings, however, provide some insights on the distribution of precipitation along the surrounding terrains. The complicated effects of topography will be investigated further with the help of additional observations and model simulations.

Acknowledgements The authors are very grateful to the constructive comments and suggestions from the anonymous reviewers. The observational data provided by the National Meteorological Information Center of CMA, the hourly ERA5 data provided by ECMWF and C3S, as well as the NCAR Command Language (2019) are also greatly appreciated. The authors would also like to thank Ms. LiangLiang Li for helping download the ERA5 data, without which it's impossible to timely improve this paper. This work was jointly supported by the National Natural Science Foundation of China (Grant nos. 41675075 and 41875112) and the National Key R\&D Program of China (Grant no. 2018YFC1507603).

Open Access This article is licensed under a Creative Commons Attribution 4.0 International License, which permits use, sharing, adaptation, distribution and reproduction in any medium or format, as long as you give appropriate credit to the original author(s) and the source, provide a link to the Creative Commons licence, and indicate if changes were made. The images or other third party material in this article are included in the article's Creative Commons licence, unless indicated otherwise in a credit line to the material. If material is not included in the article's Creative Commons licence and your intended use is not permitted by statutory regulation or exceeds the permitted use, you will need to obtain permission directly from the copyright holder. To view a copy of this licence, visit http://creativecommons.org/licenses/by/4.0/.

\section{References}

Bao X, Zhang F (2013) Evaluation of NCEP-CFSR, NCEP-NCAR, ERA-Interim, and ERA-40 reanalysis datasets against independent sounding observations over the Tibetan Plateau. J Clim 26:206214. https://doi.org/10.1175/JCLI-D-12-00056.1

Bauer P, Thorpe A, Brunet G (2015) The quiet revolution of numerical weather prediction. Nature 525:47-55

Bonner WD (1989) NMC overview: recent progress and future plans. Weather Forecast 4:275-285

Carbone RE, Conway JW, Crook NA, Moncrieff MW (1990) The generation and propagation of a nocturnal squall line. Part I: observations and implications for mesoscale predictability. Mon Weather Rev 118:26-49

Carbone RE, Tuttle JD, Ahijevych DA, Trier SB (2002) Inferences of predictability associated with warm season precipitation episodes. J Atmos Sci 59:2033-2056

Chen S, Lin Y (2005) Orographic effects on a conditionally unstable flow over an idealized three-dimensional mesoscale mountain. Meteorol Atmos Phys 88:1-21

Chen Y, Zhai P (2015) Mechanisms for concurrent low-latitude circulation anomalies responsible for persistent extreme precipitation in the Yangtze River Valley. Clim Dyn 47:989-1006

Chen H, Yu R, Li J, Yuan W, Zhou T (2010) Why nocturnal longduration rainfall presents an eastward-delayed diurnal phase of rainfall down the Yangtze River valley. J Clim 23:905-917

Chen H, Li J, Yu R (2017) Warm season nocturnal rainfall over the eastern periphery of the Tibetan Plateau and its relationship with rainfall events in adjacent regions. Int J Climatol 38(13):4786-4801

Copernicus Climate Change Service (C3S) (2017) ERA5: Fifth generation of ECMWF atmospheric reanalyses of the global climate. Copernicus Climate Change Service Climate Data Store (CDS). https://cds.climate.copernicus.eu/cdsapp\#!/home

Fritsch JM, Carbone RE (2004) Improving quantitative precipitation forecasts in the warm season: a USWRP research and development strategy. Bull Am Meteorol Soc 85:955-966

Gao Y, Xu J, Chen D (2015) Evaluation of WRF mesoscale climate simulations over the Tibetan Plateau during 1979-2011. J Clim 28:2823-2841

Hersbach Hans, Dee Dick (2016) ERA5 reanalysis is in production. ECMWF Newsl No 147:7

Hersbach H, Bell B, Berrisford P et al (2019) Global reanalysis : goodbye ERA-Interim, hello ERA5. ECMWF Newsl No 159:17-24. https://doi.org/10.21957/vf291hehd7

Jin X, Wu T, Li L (2013) The quasi-stationary feature of nocturnal precipitation in the Sichuan Basin and the role of the Tibetan Plateau. Clim Dyn 41:977-994

Konrad CE (1997) Synoptic-scale features associated with warm season heavy rainfall over the interior Southeastern United States. Weather Forecast 12:557-571

Lee J (1942) The nighttime precipitation in the Red Basin of Szechuan, China. Acta Meteorol Sin 16(S1):36-53 (in Chinese)

Li J, Yu R (2014) Characteristics of cold season rainfall over the Yungui Plateau. J Appl Meteorol Climatol 53:1750-1759

Li J, Yu R, Zhou T (2008) Seasonal variation of the diurnal cycle of rainfall in southern contiguous China. J Clim 21:6036-6043

Li Y, Li D, Yang S, Liu C, Zhong A, Li Y (2010) Characteristics of the precipitation over the eastern edge of the Tibetan Plateau. Meteorol Atmos Phys 106:49-56

Li J, Yu R, Yuan W, Chen H (2011) Changes in duration-related characteristics of late-summer precipitation over Eastern China in the past 40 years. J Clim 24:5683-5690

Li D, Wang L, Zou L (2016) Analysis of strong precipitation in a continuous warm area in the Western Sichuan Plateau. Plateau Mt Meteorol Res 36(1):81-85 (in Chinese) 
Lin Z (2015) Analysis of Tibetan Plateau vortex activities using ERAinterim data for the period 1979-2013. J Meteorol Res 29:720 734. https://doi.org/10.1007/s13351-015-4273-x

Meehl GA, Arblaster JM (1998) The Asian-Australian monsoon and El Niño-Southern oscillation in the NCAR Climate system model. J Clim 11:1356-1385

Peng G, Chai F, Zeng Q, Yu R (1994) Research on "Ya-An-Tian-Lou" part I: weather analysis. Chin J Atmos Sci 18(4):466-475 (in Chinese)

Peng G, Lu P, Li Y (2008) Synoptic study on "8.26" Yaan torrential rain in August 2003. Plateau Mt Meteorol Res 28(3):27-36 (in Chinese)

Phillips TJ, Gleckler PJ (2006) Evaluation of continental precipitation in 20th century climate simulations: the utility of multimodel statistics. Water Resour Res 42:W03202. https://doi. org/10.1029/2005WR004313

Smith RB, Barstad I (2004) A linear theory of orographic precipitation. J Atmos Sci 61:1377-1391

Smolarkiewicz PK, Rotunno R (1989) Low Froude number flow past three-dimensional obstacles. Part I: baroclinically generated lee vortices. J Atmos Sci 46:1154-1164

Sun W, Li J, Yu R, Yuan W (2018) Circulation structures leading to propagating and non-propagating heavy summer rainfall in central North China. Clim Dyn 51:3447-3465

Teixeira MS, Satyamurty P (2007) Dynamical and synoptic characteristics of heavy rainfall episodes in Southern Brazil. Mon Weather Rev 135:598-617

The NCAR Command Language (Version 6.6.2) [Software] (2019) Boulder, Colorado: UCAR/NCAR/CISL/TDD. 10.5065/ D6WD3XH5

Wang Z (1977) The Formation and Forecast of "Sky Leak" in Ya' an. Meteorol Sci Technol Data 1(S1):66-74 (in Chinese)

Wang A, Zeng X (2012) Evaluation of multireanalysis products with in situ observations over the Tibetan Plateau. J Geophys Res Atmos 117:1-12. https://doi.org/10.1029/2011JD016553

Wang B, Huang Y, Wei D, Wang J, Liu X, Huang W, Liu W, Yang X (2017) Structure analysis of heavy precipitation over the eastern slope of the Tibetan Plateau based on TRMM data. Acta Meteorol Sin 75(6):966-980 (in Chinese)

Xi G (1992) Climatic characteristics of Ya' an regional heavy rainfall. J Sichuan Meteorol 1(12):7-15 (in Chinese)

Xin X, Yu R, Zhou T, Wang B (2006) Drought in late spring of South China in recent decades. J Clim 19:3197-3206

$\mathrm{Xu} \mathrm{Y,} \mathrm{Xu} \mathrm{C-H} \mathrm{(2012)} \mathrm{Preliminary} \mathrm{assessment} \mathrm{of} \mathrm{simulations} \mathrm{of} \mathrm{climate}$ changes over China by CMIP5 multi-models. Atmos Ocean Sci Lett 5:489-494
Yu R, Li W, Zhang X, Liu Y, Yu Y, Liu H, Zhou T (2000) Climatic features related to Eastern China summer rainfalls in the NCAR CCM3. Adv Atmos Sci 17:503-518

Yu R, Wang B, Zhou T (2004) Tropospheric cooling and summer monsoon weakening trend over East Asia. Geophys Res Lett 31:L22212. https://doi.org/10.1029/2004GL021270

Yu R, Xu Y, Zhou T, Li J (2007a) Relation between rainfall duration and diurnal variation in the warm season precipitation over central eastern China. Geophys Res Lett 34:L13703. https://doi. org/10.1029/2007GL030315

Yu R, Zhou T, Xiong A, Zhu Y, Li J (2007b) Diurnal variations of summer precipitation over contiguous China. Geophys Res Lett 34:L01704. https://doi.org/10.1029/2006GL028129

Yu R, Yuan W, Li J (2013) The asymmetry of rainfall process. Chin Sci Bull 58:1850-1856

Yu R, Chen H, Sun W (2015) The definition and characteristics of regional rainfall events demonstrated by warm season precipitation over the Beijing plain. J Hydrometeorol 16:396-406

Yuan W, Yu R, Chen H, Li J, Zhang M (2010) Subseasonal characteristics of diurnal variation in summer monsoon rainfall over Central Eastern China. J Clim 23:6684-6695

Yuan W, Xu H, Yu R, Li J, Zhang Y, He N (2018) Regimes of rainfall preceding regional rainfall events over the plain of Beijing City. Int J Climatol 38:4979-4989

Zeng Q, Yu R, Peng G, Chai F (1994) Research on "Ya-An-Tian-Lou" part III: the physical structure and possible mechanism. Chin J Atmos Sci 18(6):649-659 (in Chinese)

Zhang Y, Xue M, Zhu K, Zhou B (2019) What is the main cause of diurnal variation and nocturnal peak of summer precipitation in Sichuan Basin, China? The key role of boundary layer low-level jet inertial oscillations. J Geophys Res 124:2643-2664

Zheng Y, Gong Y, Chen J, Tian F (2019) Warm-season diurnal variations of total, stratiform, convective, and extreme hourly precipitation over Central and Eastern China. Adv Atmos Sci 36:143-159

Zhou C, Wu P (2015) Comparison analysis of two warm sector torrential rain weathers on the east side of Tibeatn Plateau. Plateau Mt Meteorol Res 35(1):1-8 (in Chinese)

Publisher's Note Springer Nature remains neutral with regard to jurisdictional claims in published maps and institutional affiliations. 